\title{
DO SUJEITO PASSIVO NO IPTU: UMA ANÁLISE SOB O ENFOQUE CONSTITUCIONAL ${ }^{1}$
}

\author{
Bruno Nogueira Rebouças, Eric Felipe Silva \\ e Rafael Ribeiro de Brito \\ Alunos do curso de Direito da FA7 \\ rebbruno@gmail.com \\ ericphelipe@hotmail.com \\ rafael_brito7@hotmail.com
}

Sumário: Introdução. 1. Brevíssima evolução histórica do IPTU. 2. Âmbito constitucional do tributo e o CTN. 3. Um tema relevante de Direito Civil. 4. Do contribuinte do IPTU. 5. Análise objetiva das leis dos principais municípios arrecadadores. 6. Considerações aos aforamentos e às ocupações dos terrenos de marinha. Conclusão. Referências.

Resumo: O tema central gira em torno da sujeição passiva surgida da obrigação que exige o pagamento do Imposto sobre Propriedade Predial e Territorial Urbana, enfrentando questões que envolvem tanto a figura do contribuinte como a do responsável tributário, terminando por discutir aspectos concernentes ao tratamento dado por esse imposto ao dito terreno de marinha, ademais de análise da legislação municipal que trata do assunto, tudo sob a ótica tanto do Direito Constitucional quanto dos institutos do Direito Privado, a tratar o ordenamento jurídico como sistema, imperativo que lhe é essencialmente inerente.

Palavras-chave: Terrenos de Marinha. Responsabilidade. Contribuinte. Sujeito Passivo. Âmbito Constitucional. IPTU.

\section{INTRODUÇÃo}

Tendo em vista as dificuldades recorrentes no entendimento das questões que envolvem a relação entre o Imposto sobre a Propriedade Predial e Territorial Urbana e o sujeito passivo da obrigação que acarreta sua cobrança, propomo-nos, sem pretensões definitivas, enfrentar o tema da sujeição passiva sob a luz da interpretação constitucional, o que se traduz em imperativo da nossa ordem jurídica. O postulado da máxima efetividade das normas constitucionais exigiu esforço que levou esse trabalho a desenvolver raciocínios que, não se distanciando da doutrina e da jurisprudência, contemplassem, seriamente, os valores constitucionais, dando, por isso mesmo, uma visão do tributo pautada na segurança jurídica, a auxiliar operadores do direito nas resoluções dos mais diversos casos concretos que possam vir a surgir. Procurou-se levantar, igualmente, questionamentos acerca de alguns pontos específicos, não olvidando de deixar clara nossa opinião que - repita-se - está longe de ser definitiva, tal qual verdade científica, que possui caráter relativo, não definitivo e absoluto. Tributaristas, dos clássicos aos mais recentes, foram aqui consultados, a fim de se garantir um maior rigor científico aos argumentos. Velhas lições, outrora esquecidas, foram de uma utilidade analítica incomensurável, sustentando argumentos a que o bom senso da razoabilidade já nos conduzira antes.

Cabe, inicialmente, depois de breve histórico do tributo, analisar a compatibilidade de seu âmbito constitucional com o Código Tributário Nacional, o que conduzirá todo o restante do argumento. 


\section{BREVÍSSIMA EVOLUÇÃo HISTÓRICA DO IPTU}

O Imposto sobre a Propriedade Predial e Territorial Urbana parece ter suas origens remotas no Brasil, em carta datada de 19-5-1799, de autoria da Rainha D. Maria, em imposto de décima incidente nas casas das cidades marinhas. (BALEEIRO, 1981, p. 153).

Já no século XX, formam previstos pelas cartas constitucionais de 1934 e 1937, na competência de instituição pelos Municípios, separadamente, os impostos predial e territorial urbano até sua unificação, a qual ocorreu só na Constituição de 1946 (conservando a competência municipal), passando a integrar um só imposto, o que acarretou consequências inafastáveis, não podendo o Município tentar impossibilitar que o imposto sobre as edificações não abranja, ao mesmo tempo, todo o terreno que a ele se ligue. (MACHADO, 2003, p.356) Não são, portanto, dois impostos cobrados separadamente, um sobre o terreno e outro sobre as edificações, mas apenas um imposto que abrange todo o imóvel.

\section{2 Âmbito constitucional do TRIBUto e o CTN}

Seria muito simples encarar esse imposto sob a ótica apenas do Código Tributário Nacional, menosprezando vinculação ao seu âmbito constitucional, haja vista que, ao seguir as diretrizes do CTN, basta à pessoa ser proprietário, possuidor a qualquer título ou detentor de domínio útil, para ser visto, efetivamente, como seu contribuinte. ${ }^{2}$

Não obstante a sedutora interpretação que daí se poderia extrair, de cunho eminentemente econômico, a beneficiar a arrecadação do Erário, pensamos que, pelo fato de a relação tributária se transfigurar numa relação de direito, e não de poder, não devemos deixar de lado os institutos jurídicos - que, em última analise, estão presentes no discurso jurídico para garantir um mínimo de segurança jurídica - nem, muito menos, a hermenêutica constitucional.

A Constituição de 1988 utilizou, expressamente, a palavra propriedade, o que gerou dissenso no meio doutrinário, quanto à adoção de tal conceito em seu sentido técnico-jurídico, visto que alguns doutrinadores (BARRETO, 2009, p.179) não consideraram que esse conceito estivesse aplicado nesse sentido, mais sim num mais amplo, não vinculado precisamente a suas origens privatísticas ou - numa análise ainda mais minuciosa - econômicas. (AMARO, 2010, p. 246)

Sustentamos que tal ponto de vista se aproxima muito mais de uma tentativa doutrinária de compatibilizar o Código Tributário Nacional à Carta Magna - como já havia sendo feito - do que dar aos institutos jurídicos sua mais segura interpretação, dando efetiva importância à interpretação que se desenvolve segundo a Constituição Federal. Luís Roberto Barroso assim se pronuncia no que se refere ao princípio da interpretação conforme a Constituição:

\footnotetext{
(...) o princípio guarda suas conexões com a unidade do ordenamento jurídico e, dentro desta, com a supremacia da Constituição. Disso resulta que as leis editadas na vigência da Constituição, assim como as que procedem de momento anterior, devem curvar-se aos comandos da Lei Fundamental e ser interpretadas em conformidade com ela. (BARROSO, 2008, p.192).
}

Pode-se ver que a própria unidade do ordenamento e a supremacia constitucional são imperativos à interpretação vinculada aos preceitos constitucionais, não maculando os conceitos que foram albergados pela Constituição, sob o risco de modificar a própria Lei Fundamental. Tal qual se extrai das palavras de Hugo de Brito Machado, admitir que a lei ordinária altere conceitos utilizados por qualquer norma da Constituição é permitir a lei modificando a própria Constituição. (MACHADO, 2011a, p. 111). 
Com toda a razão, o arguto jurista não menospreza o fato de se atribuir ao conceito de propriedade, para fins de determinação de competência para instituir o IPTU, o seu sentido técnico-jurídico, argumentando, ao refutar quem pensa em contrário:

\begin{abstract}
Não me parece, porém, que seja esta a explicação mais adequada. Penso que a palavra propriedade está empregada na Constituição em sentido rigorosamente jurídico, e mesmo assim não vejo invalidade alguma no dispositivo do Código Tributário Nacional que se refere ao domínio útil e à posse ao descrever o âmbito constitucional do imposto em questão. (MACHADO, 2003, p. 359)
\end{abstract}

Surge, porém, um questionamento: Como deve ser vista a posse para melhor se compatibilizar com o referido conceito de propriedade? Primeiramente, não nos parece que a posse deve ser classificada como direito, mas sim como fato, haja vista não se localizar, a priori, no plano dos efeitos, porém no plano fático que o antecede. ${ }^{3}$ Ademais, não se deve confundir a posse com o direito à posse, já que a primeira independe totalmente da prévia existência de propriedade, enquanto que o segundo pode, perfeitamente, dela decorrer. Em segundo lugar, a posse em si como um todo não é inerente ao direito de propriedade, sendo algo bem mais amplo que isso. $\mathrm{O}$ direito à posse é, sim, inerente ao direito de propriedade. A posse como fato em si pode ser apenas uma exteriorização sua, mas não lhe é inerente. A ação de imissão de posse transfigura bem isso, a dar direito à efetivação da posse ao proprietário que não a deteve. Uma prova de que a posse deve ser vista mais como fato (essencialmente) do que como direito, é exemplificada na dita posse de má-fé que seja ao mesmo tempo injusta (NADER, 2008, p. 47). Não podemos dizer que o possuidor de má-fé seja verdadeiramente detentor de um genuíno direito à posse, porém não deixa de ser possuidor da coisa (mesmo que injusto e de má-fé).

Por último, há de se reconhecer que uma posse injusta e de má-fé, ao mesmo tempo, de bem imóvel, pode, perfeitamente, se submeter à usucapião extraordinária.

No mais, seria mais cauteloso falar-se da posse, para efeitos de IPTU, como um fato que é a exteriorização da propriedade, no caso. E, quando exercido, precisa ao menos estar vinculado a ela (propriedade) (a) quanto às suas características inerentes que a individualizam ou (b) com potencialidade significativa de sua concreção jurídica num futuro. Não é, portanto, qualquer posse que caracteriza o contribuinte de direito do IPTU, mas uma posse com características próprias, exteriorizando faticamente os poderes de proprietário ou potencialmente dando essa breve possibilidade à pessoa. Argumenta Sacha Calmon que

\footnotetext{
Nesse sentido é que o Código Tributário Nacional tomou a posse e a enfiteuse. Tomou-as, noutro giro, como "signos presuntivos", para usar expressão a gosto de Becker, de um direito de propriedade tributável, conforme previsto na Constituição, até porque a posse e a enfiteuse, nesta acepção vimos de ver, configuram muito aquele domínio econômico - expressão de capacidade contributiva - lembrado por Hensel. (COÊLHO, 1990, p. 253)
}

O que quer dizer o autor é que a Constituição não inovou, criando impostos sobre a posse e o domínio útil (COÊLHO, 1990, p. 252); no entanto, a tributação sob essas condições não está excluída, desde que signifiquem "signos presuntivos" de propriedade, ou seja, exteriorizando-a faticamente (v.g., enfiteuse) ou potencialmente (v.g., posse ad usucapionem). Veja que a posse do locatário, se bem que possa ser identificada como domínio útil (GUIMARÃES, 2008, p. 284), não exterioriza nem faticamente (haja vista não dar o poder de dispor economicamente da coisa) nem exterioriza potencialmente (visto nunca poder o locatário se tornar proprietário) a propriedade. A priori, o contribuinte do IPTU sempre será o proprietário, a quem a Fazenda poderá cobrar e executar suas dívidas. ${ }^{4}$

Em suma, pode-se propor que a compatibilização do Código Tributário Nacional com a Constituição Federal não seriam meramente obra do acaso, mas um esforço doutrinário e 
jurisprudencial relativamente corriqueiro que termina por sustentar harmonicamente os dois textos normativos, sem desvincular sua interpretação um do outro. Segundo lição de Norberto Bobbio,

A terceira solução - conservar as duas normas incompatíveis - é talvez aquela a qual o interprete recorre mais frequentemente. Mas como é possível conservar duas normas incompatíveis, se por definição duas normas incompatíveis não podem existir? É possível sob uma condição: demonstrar que não são incompatíveis, que a incompatibilidade é puramente aparente, que a pressuposta incompatibilidade deriva de uma interpretação ruim, unilateral, incompleta ou errada de uma das normas ou de ambas. (BOBBIO, 1999, p. 102)

\section{Um tema Relevante de Direito Civil}

Pode ser classificado como tema relevante a ser tratado, a título do entendimento da adoção do conceito de propriedade em seu sentido técnico-jurídico no âmbito constitucional do tributo abordado e a compatibilização constitucional do CTN em matéria de IPTU, a adoção da Teoria Objetiva da posse pelo ordenamento jurídico brasileiro e suas razões.

Quanto à adoção da Teoria Objetiva da posse como regra no nosso ordenamento jurídico, declara Clóvis Beviláqua (1942, p. 5): “O Código Civil brasileiro foi o primeiro a consagrar, inteira e francamente, a doutrina de Jhering sobre a posse".

Posteriormente falando que

Jhering, sem negar a influência da vontade na conceituação da posse, acha que não tem aqui acção mais preponderante do que em qualquer relação jurídica, e compreende a posse como "a relação de facto estabelecida, entre a pessoa e a coisa, pelo fim de sua utilização econômica” (Der Besitzwille, p. 481). (BEVILAQUA, 1942, p. 9)

Essa ideia se opõe a que é trazida por Savigny (Teoria Subjetiva), a qual possui no seu núcleo a vontade de ser dono, valorizando o denominado animus domini, Tal qual se pode deduzir do seguinte:

Posse "é o poder que tem uma pessoa de dispor, physicamente, de uma coisa, acompanhado na intenção de te-la para si (animus domini, animus rem sibi abendi)." Resulta da combinação dos dois elementos: o poder physico (corpus) e a intenção de ter para si (animus). (IDEM, 1942, p. 8)

O nosso Direito Civil não consagrou como regra a Teoria Subjetiva, o que nos autoriza a dizer que nos seria irrelevante saber se a pessoa possui a coisa com intenção de torná-la sua ou não, a fim de configurar a figura do possuidor. Caso contrário, o locatário, o comodatário e o arrendatário, por exemplo, não poderiam ser vistos como possuidores, o que nos representaria verdadeiro absurdo. A redação do Código Civil vigente, em seu artigo 1196, prescreve o seguinte: "Art. 1196. Considera-se possuidor todo aquele que tem de fato o exercício, pleno ou não, de algum dos poderes inerentes à propriedade." 5 Observe-se que tal preceito normativo é mera reprodução do texto original do artigo 485 do Código Civil de 1916 (“Código Beviláqua”), o qual consagrou a dita Teoria Objetiva da posse. Isso não quer dizer que a Teoria Subjetiva não pode ser aplicada excepcionalmente, mas sempre com o cuidado de não macular a essência da teoria por nós adotada. Sua mais nítida exceção se encontra na usucapião, na qual se exige o requisito da continuidade e da tranquilidade (objetivo) e do animus domini (subjetivo) (BEVILAQUA, 1942, p. 92). A doutrina admite, pacificamente, que a posse ad usucapionem pressupõe o animus domini, o que demonstra a aproximação dos tribunais superiores em aceitar a cobrança do IPTU de quem detém o dito animus domini ${ }^{61} \mathrm{e}$, por consequência, de quem tem a posse ad usucapionem, 
tornando-o contribuinte. Há, porém, requisitos de caráter objetivo, como os apontados por Beviláqua (continuidade e tranquilidade) que autorizam falar-se de posse ad usucapionem, não bastando o mero animus domini para configurá-la, e isso para o nosso raciocínio aqui desenvolvido é o que interessa, visto que se perfaz insuficiente falar-se de animus de ser dono para configurar o contribuinte do IPTU. A existência ou não de animus dimini é algo muito subjetivo, varia de pessoa para pessoa, o que cria uma insegurança no momento de se identificar a posse com tal característica. Não seria em vão, portanto, a tentativa do legislador de criar requisitos de caráter objetivo (v.g., um prazo prescricional e pacificidade), haja vista que pelo mero fato de o indivíduo estar habitando ou produzindo em imóvel alheio já o autoriza à presunção de tê-lo para si, ou seja, tornar-se dono (animus domini). No caso do arrendatário, do locatário, do comodatário, por exemplo, não é que esse animus não exista, mas ele é presumivelmente inexistente, embasando-se na impossibilidade fática de o indivíduo tornar-se efetivamente dono (dono em potencial) da coisa e não exteriorizar, de fato, a propriedade. Uma prova disso, é que na própria teoria de Savigny, a fim de se buscar uma maior segurança, ele incluiu (como foi visto da tradução feita por Beviláqua de sua teoria) o poder fático de dispor da coisa, não bastando o animus domini para ser possuidor. Assim também concluiu Silvio Rodrigues, ao dizer que "Para Savigny a posse é o poder de dispor fisicamente da coisa, com ânimo de considerá-la sua e defendê-la contra a intervenção de outrem. " (RODRIGUES, 1988/94, p.18).

Podemos resumir a questão, com a crítica feita por Pontes de Miranda às teorias subjetivistas da posse.

\footnotetext{
Todas essas teorias, como as outras, que não renunciaram à fácil explicação pelas exceções ao princípio do animus domini, procuraram definir o que é suporte fático da relação jurídica possessória. Animus domini, animus dominandi, - tais as expressões de que se usava, revelando todas o subjetivismo que as informava (animus, opinio, cogitatio domini). (MIRANDA, 1971, p. 28)
}

Tendo isso em vista, preenchidos os requisitos da usucapião, poderíamos dizer, ao menos informalmente, que teria havido algo ao menos semelhante ao abandono do imóvel (diferentemente da renúncia, que é ato formal), por razões de tempo, posse mansa e pacífica, etc. Daí falarmos que temos na posse ad usucapionem ${ }^{7}$ como "signo presuntivo de propriedade", o que autoriza classificar esse possuidor como contribuinte do Imposto sobre Propriedade Predial e Territorial Urbana.

\title{
4 Do CONTRIBUINTE Do IPTU
}

Pode-se assim definir contribuinte:

\begin{abstract}
É o sujeito da relação tributária que mantém relação pessoal e direta com o fato gerador desta. Distingue-se do responsável, que também é sujeito passivo da obrigação tributária, exatamente porque este não tem relação pessoal e direta com o fato gerador, decorrendo seu dever de pagar o tributo de dispositivo expresso em lei. (MACHADO; MACHADO, 2011b, p. 49).
\end{abstract}

O contribuinte, segundo Rubens Gomes de Sousa, é o sujeito passivo direto da relação tributária (SOUZA, 1982, p.91), não se confundindo com o sujeito passivo indireto, que se dá por (a) transferência (pode ser solidariedade, sucessão e responsabilidade) ou por (b) substituição (IDEM, 1982, p. 92). A substituição não deixa de ser responsabilidade. Do que já foi exposto neste trabalho, tomou-se que o contribuinte do IPTU deve ser, prima facie, o proprietário, visto que se deve interpretar o CTN à luz da Constituição de 1988 para não recorrer à sua invalidade, dando máxima efetividade aos preceitos constitucionais. Por isso, o CTN, quando trata do detentor de 
domínio útil, deve-se ter em vista que ele se refere, exclusivamente, ao instituto da enfiteuse, e nada mais, visto que "A enfiteuse é o direito mais amplo sobre a coisa alheia" (COÊLHO, 1990, p. 254). O enfiteuta adquire todos os poderes inerentes do domínio (IDEM, p.254), podendo usar, gozar, reivindicar e dispor economicamente da coisa. Ele se perfaz em genuíno proprietário atípico, possuindo o direito de propriedade ao menos em potencial. O fato de ele poder dispor economicamente da coisa se coaduna com a ideia de se identificar um tributo por seu núcleo, sendo, por consequência, núcleo de sua própria hipótese de incidência, qual seja, segundo Alfredo Augusto Becker, a base de cálculo do tributo, no caso do Imposto sobre Propriedade Predial e Territorial Urbana. (BECKER, 2010, p. 425). A partir do momento que a lei define a base de cálculo do IPTU como o valor venal do imóvel, está confirmando que o tributo que está sendo criado é mesmo o que veio previsto como IPTU constitucionalmente, caso contrário seria outro imposto, mas não o IPTU. Dado tal fato, a ideia central do legislador constituinte, o que só confirma o que trabalhamos até agora, é tributar quem expõe (mesmo que potencialmente) tal poder de dispor economicamente da coisa, o que também fundamenta a classificação do dito promitente-comprador (quando do registro do contrato de compromisso) como verdadeiro contribuinte. ${ }^{8}$ A importância da base de cálculo para definir a hipótese de incidência do tributo é elevada por Geraldo Ataliba.

Daí por que - enquanto aspecto da h.i. - a base imponível é um conceito-legal, a que fica preso o intérprete. É qualidade jurídico-normativa da h.i. A mensuração do fato imponível só pode ser feita de acordo com o critério normativo que na base de cálculo (legal) se adota. (ATALIBA, 2010, p.110)

Também fala que:

A.Becker desenvolve longo raciocínio, para mostrar - como já o fizeram Rubens Gomes de Sousa, Amílcar Falcão e Gilberto de Ulhoa Canto - que, no caso de o aspecto material ser muito complexo, será essencialmente importante e decisivo o elemento do fato cuja perspectiva dimensível for qualificada pelo legislador como base imponível. (IDEM, 2010, p.111)

O valor econômico da base de cálculo de um tributo que se liga ao estado de fato jurídico que se relaciona à existência de direito (BECKER, 2010, p.457) (no caso, direito real de propriedade) deve vincular quem pode revertê-lo economicamente em seu proveito, que, por causa exatamente disso, ele estaria sendo cobrado, não por algo que fugisse completamente da sua base de cálculo - consequentemente não estando na essência da hipótese de incidência -, como se daria nos casos dos rendimentos auferidos devido ao uso ou usufruto daquele bem.

Tomando por base o exposto, discordamos da decisão em que o Superior Tribunal de Justiça vislumbrou como contribuinte do IPTU o usufrutuário ${ }^{9}$, o qual, em verdade, se limita aos poderes de uso e fruição (NADER, 2008, p.331). Tal equívoco se dá devido a uma interpretação ligeira e não cautelosa do artigo 1403, inciso II, do Código Civil, o qual versa:

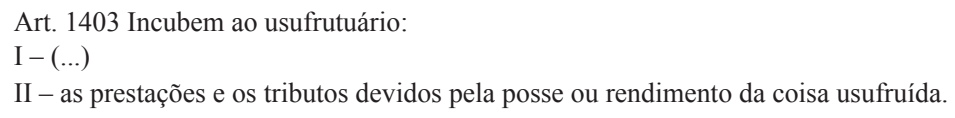

Primeiramente, não é a posse que gera o dever de pagar o IPTU, como já foi exaustivamente discutido aqui, mas sim a propriedade, e o texto é claríssimo ao falar que o dever de pagar prestações e tributos deve decorrer do fato da posse. Pelo menos no sistema tributário brasileiro, atualmente, não existe tributo que decorre da posse, não havendo óbice de sua criação por lei complementar, utilizando-se da competência residual dada à União (artigo 154, I, da Constituição Federal) para criar tributos, desde que sejam não cumulativos e não tenham fato gerador ou base da cálculo daqueles já discriminados constitucionalmente (MACHADO, 2010, 
p. 209 e 210). Em segundo lugar, o rendimento da coisa usufruída, representando acréscimo patrimonial já será tributado pessoalmente pelo imposto de renda, sendo a bitributação vedada.

De resto, o locatário ${ }^{10}$, o arrendatário $^{11}$, o comodatário ${ }^{12}$, o permissionário ${ }^{13} \mathrm{o}$ concessionário $^{14}$, possuidor de servidão de passagem ${ }^{15}, \mathrm{o}$ usuário, o habitador, nenhum deles pode ser sujeito passivo direto na relação tributária que acarreta a cobrança do Imposto sobre Propriedade Predial e Territorial Urbana. Já o enfiteuta ${ }^{16}$, assim como o promitente-comprador e o que já comprou ${ }^{17}$ podem ser, perfeitamente, contribuintes do imposto.

Afirma, peremptoriamente, a famigerada tributarista Misabel Abreu Machado Derzi, em comentários de atualização a Aliomar Baleeiro (2010, pp. 245 e 246) "Não podem configurar fato gerador do IPTU a posse a qualquer título, a precária ou clandestina, ou a direta do comodatário, do locatário, do arrendatário, de detentor, do usufrutuário, do administrador de bem de terceiro, etc. que jamais se tornarão propriedade".

A professora nos dá mais embasamento para discordar do fundamento utilizado pelo Superior Tribunal de Justiça, ao dar importância desmesurada à distinção entre posse decorrente de direitos reais (v.g., usuário, habitador, usufrutuário) da de direitos pessoais (v.g., locatário, comodatário), o que não altera o alcance constitucional do tributo em questão.

Por fim, discordamos da justificativa dos tribunais quando fundamentam suas decisões apenas na existência ou não do animus domini, já que demonstramos ser problemático tal parâmetro levado isoladamente em consideração. O que nos leva à conclusão de que o possuidor $a d$ usucapionem pode ser contribuinte do IPTU estaria no fato de ele ser potencialmente e aparentar socialmente ser proprietário, havendo "signo presuntivo" de direito de propriedade em sua posse.

\section{ANÁlise OBJETIVA dAS LEIS DOS PRINCIPAIS MUNICÍPIOS ARRECADADORES}

O anseio, cada vez maior, por parte dos Entes Fazendários Municipais pela majoração na arrecadação do Imposto que ora versamos, traz conotações que, como seguimos a demonstrar, não merecem prosperar.

Furtando-se do dever de observância à interpretação da norma à luz da sistemática técnico-jurídica, como exaustivamente tratamos, é imperioso destacar a claríssima ofensa ao texto normativo constitucional, o que, indiscutivelmente, faz reverberar situações fáticas desarmoniosas ao intento primeiro do legislador originário.

Diferentemente deste entendimento é o que vem sendo aplicado pelas Leis Municipais, que instituem as formas de arrecadação do IPTU, onde encontraremos, ademais de outras características, um caráter preponderantemente econômico.

Sem muito esforço intelectivo, podemos chegar a esta conclusão através da análise direta dos dispositivos normativos de algumas das cidades que mais arrecadam o tributo sobre o qual nos debruçamos, quando trazem em seu bojo a referência direta não só ao proprietário, mas também ao mero possuidor, o que, a nosso ver, não parece razoável.

Alguns dos maiores arrecadadores como São Paulo $\left(1^{\circ}\right)$, Rio de Janeiro $\left(2^{\circ}\right)$, Campinas $\left(5^{\circ}\right)$, Goiânia $\left(7^{\circ}\right)$, São Bernardo do Campo $\left(8^{\circ}\right)$, Guarulhos $\left(9^{\circ}\right)$, Salvador $\left(10^{\circ}\right)$ e Fortaleza* $\left(18^{\circ}\right)$ às cegas, e não acompanhados da melhor interpretação filológica, tratam da questão como mera extensão do art. 34 do CTN.

Verifica-se, então, quanto ao contribuinte, que as Leis Municipais, em infeliz ou, quiçá, em proposital escolha, reproduzem o referido artigo, sem, contudo, em seu procedimento 
fático-administrativo, aplicar-lhe o legítimo sentido, quando consideram ser legítimos a contribuir o "proprietário, o titular do domínio útil e o possuidor a qualquer título [grifo próprio]." 18

Ora, outro fator não poderá ser levado em consideração, senão o fato gerador, para que o tributo possa ser devidamente atribuído. Em se tratando do IPTU, diz-se que o fato gerador é exatamente o fato que externa o direito da propriedade, o que nos reprimenda concluir que aqueles outros a que as leis alhures citadas insistem em elencar, não poderiam, jamais, versar neste polo. E não ecoa solitária nossa voz, visto que assim decidiu o Superior Tribunal de Justiça ${ }^{19}$.

Como não bastassem as negligentes considerações que as Leis Municipais ${ }^{20}$ nos apresentam quanto à pessoa do contribuinte, trazem, também, ademais dessa figura, outras, que, pela mera conveniência foram tratadas como responsáveis tributários, o que, por semelhante argumento, não têm razão de ser. Analisemos:

\begin{tabular}{|c|c|}
\hline MUNICÍPIO & RESPONSÁVEIS \\
\hline $\begin{array}{l}\text { São Paulo - SP } \\
\left(1^{\circ}\right)\end{array}$ & $\begin{array}{l}\text { DECRETO } \mathrm{N}^{\circ} 52.703 \text {, ART. 12: O imposto é devido, a critério da repartição } \\
\text { competente: I - por quem exerça a posse direta do imóvel, sem prejuízo da } \\
\text { responsabilidade solidária dos possuidores indiretos; II - por qualquer dos possuidores } \\
\text { indiretos, [grifo próprio] sem prejuízo da responsabilidade solidária dos demais e do } \\
\text { possuidor direto. } \\
\text { Parágrafo único. O disposto neste artigo aplica-se ao espólio das pessoas nele referidas. }{ }^{21}\end{array}$ \\
\hline $\begin{array}{l}\text { Rio de Janeiro - RJ } \\
\left(2^{\circ}\right)\end{array}$ & $\begin{array}{l}\text { DECRETO No } 14.327 \text {, ART. 16, P. U: São também contribuintes: } \\
\text { I - os promitentes compradores imitidos na posse conforme título devidamente } \\
\text { registrado no Registro de Imóveis; II - os posseiros; III - os ocupantes ou } \\
\text { comodatários de imóveis pertencentes à União, aos Estados, ao Município ou } \\
\text { quaisquer outras pessoas isentas do imposto ou a ele imunes. [grifo próprio] }{ }^{22}\end{array}$ \\
\hline $\begin{array}{l}\text { São Bernardo do } \\
\text { Campo - SP }\left(8^{\circ}\right)\end{array}$ & $\begin{array}{l}\text { LEI No } 1802 \text {, ART. } 98: 0 \text { imposto é devido, a critério da repartição competente: I - por } \\
\text { quem exerça a posse direta do imóvel, sem prejuízo da responsabilidade solidária } \\
\text { dos possuidores indiretos; II - por qualquer dos possuidores indiretos, [grifo próprio] } \\
\text { sem prejuízo da responsabilidade solidária dos demais e do possuidor direto. } 23\end{array}$ \\
\hline Guarulhos - SP $\left(9^{\circ}\right)$ & $\begin{array}{l}\text { LEI N }^{\circ} 6.793, A R T .8^{\circ} \text { : São solidariamente responsáveis pelo pagamento do Imposto } \\
\text { sobre a Propriedade Predial e Territorial Urbana - IPTU: } \\
\text { I - o co-proprietário; II - o compromissário comprador; III - o superficiário; IV - o } \\
\text { titular do direito de usufruto, uso, enfiteuse ou fideicomisso; V - os cessionários; } \\
\text { VI - o adquirente, ainda que beneficiário de imunidade ou isenção, pelo débito do } \\
\text { alienante.[grifo próprio]. } 24\end{array}$ \\
\hline Salvador - BA $\left(10^{\circ}\right)$ & $\begin{array}{l}\text { LEI No } 7.186 \text {, ART. } 63, \S \S 1^{\circ}: \S 1^{\circ} \text { Respondem pelo imposto os promitentes- } \\
\text { compradores, os cessionários, os comodatários e os ocupantes a qualquer título } \\
\text { do imóvel, ainda que pertencente à pessoa física ou jurídica de direito público ou } \\
\text { privado isenta do imposto ou imune. [grifo próprio] } 25\end{array}$ \\
\hline Fortaleza - CE $\left(1^{\circ}\right)$ & $\begin{array}{l}\text { LEI No } 4.144 \text { ART. } 110, \S \S 1^{\circ}, 2^{\circ} \text { E } 3^{\circ}: \S 1^{\circ} \text { São responsáveis pelo pagamento do } \\
\text { imposto, além do contribuinte definido neste artigo: I-o titular do direto de usufruto, } \\
\text { de uso ou habitação; II -o compromissário comprador; III - o comodatário ou credor } \\
\text { anticrético.[grifo próprio] } 26\end{array}$ \\
\hline
\end{tabular}


Em verdade, o Art. 128 do CTN institui, sim, a possibilidade da indicação de responsáveis em relação ao tributo, atendidas as disposições indispensáveis para isso, entretanto.

Como já vergastado outrora, a posse nem sempre será um direito decorrente da propriedade, estando evidentemente mais próxima do campo da faticidade. Destarte, em se trilhando o harmonioso iter interpretativo, inafastável simetria aplicável às normas infraconstitucionais, o próprio artigo 128 do Código Tributário Nacional aduz com luminescência solar o que nos parece ser o verdadeiro espírito normativo, motivo pelo qual, mais uma vez, sussurra-nos a impossibilidade de outro sujeito figurar nessa relação, que não o proprietário (considerando as observações já tratadas), pois é impossível haver a subsunção fático-normativa, nestes termos.

Baseado nisso é que categoricamente se pode afirmar: Ora, se a posse, por si só, como fato, não tem correlação direta com o âmbito constitucional do imposto, com muito maior razão, não há se falar em responsabilidade por parte de outros, pelos mesmos motivos retro-aduzidos. As leis municipais não se adequam à previsão constitucional do tributo ao falar de responsabilidade, já que a Constituição limita a determinação de qualquer sujeito passivo; seja direto, seja indireto (BARRETO, 2009, p. 365). Ademais, como se pôde verificar, algumas leis cometem até mesmo a atecnia de chamar o "responsável" (strictu sensu) de "contribuinte", como se uma só coisa fossem, o que, sabemos, não é verdade, pois são completamente distintos em suas naturezas.

Em outras palavras, verifica-se o óbice quanto à instituição de responsáveis pelo tributo pela limitação que o artigo 128 do CTN traz, visível, especificamente, no caso do IPTU, porque, em destacadas disposições facilmente verificadas na listagem acima, não existe vínculo entre estes e o fato gerador da referida norma que autorize a responsabilização. (PACHECO, 1995, p. 18)

\section{CONSIDERAÇÕES AOS AFORAMENTOS E ÀS OCUPAÇÕES DE TERRENOS DE MARINHA}

Em nosso artigo, também nos coube discorrer acerca das ocupações e dos aforamentos dos terrenos de marinha, mostrando a falta ou não de legitimidade do possuidor em ser tributado no que tange ao Imposto sobre a Propriedade Predial e Territorial Urbana no caso dos aforamentos e de ocupações.

Perfaz-se, no entanto, precípuo que esteja clara a distinção entre aforamento e ocupação. Como se sabe, de acordo com a Constituição Federal de 1988, em seu art.20, VII, são bens da União os terrenos de marinha e seus acrescidos.

No aforamento, tem a União o domínio direto do bem, podendo disponibilizar o seu domínio útil, para ser usufruído por um particular. A quem é dado este direito, denominamos foreiro, ou enfiteuta, já que poderá usar, gozar, reivindicar e dispor economicamente da coisa, como já fora dito anteriormente. Neste caso, o foreiro tem a garantia de posse mediante o pagamento da taxa de aforamento, sendo esta cobrada anualmente.

O domínio útil pode ser tranquilamente transferido a outrem, devendo ser paga à União uma taxa na qual denominamos laudêmio. Podemos perceber que se apresentam inerentes ao foreiro, os já mencionados "signos presuntivos" de propriedade.

Já o ocupante, é a pessoa física ou jurídica que está autorizada pela SPU (Secretaria do Patrimônio da União) a ocupar imóvel de propriedade da União. Entretanto, embora o ocupante tenha o dever de pagar a taxa de ocupação, como já nos diz Danilo Oliveira R. de Lima, em seu artigo $A$ verdade e a ocupação dos terrenos de marinha, a inscrição administrativa da "ocupação", "é um ato administrativo precário, que pode ser cancelado quando houver interesse do serviço público, de modo que a utilização desses imóveis por particulares sob "regime de 
ocupação" é uma situação de fato, pois aqueles não adquirem titularidade de qualquer direito real sobre o bem público ocupado, ou sobre as benfeitorias nele edificadas, não possuindo sequer direito ao aforamento" 27 .

Vejamos que, diferentemente do aforamento, embora a União venha executando costumeiramente, há uma incompatibilidade na cobrança de laudêmios no caso da ocupação, pois a mesma não é prevista no art. $3^{\circ}$ do Decreto-Lei n ${ }^{\circ} 2.398 / 87$. Alguns Tribunais Regionais Federais e o próprio Superior Tribunal de Justiça já estão reconhecendo esta realidade.

Defendemos então que, por tratar-se de regime de enfiteuse, o foreiro poderá ser cobrado tanto da taxa de foro, que não possui natureza tributária, quanto do IPTU; por demonstrar em sua posse a exteriorização da propriedade, enquanto no simples regime de ocupação de terrenos de marinha, por ter caráter precário, que poderá ser extinto a qualquer momento, quando assim for do interesse do serviço púbico, e por não tratar-se, também, de direito real, o possuidor deverá apenas ser cobrado no que tange à taxa de ocupação.

\section{Conclusão}

O que aqui foi exposto só demonstra o quão apressadas - com raras exceções ${ }^{28}$ - são as conclusões deduzidas do tema, em sua total abrangência, pelos tribunais superiores (notadamente o Superior Tribunal de Justiça) hoje, no Brasil, a ignorar as repercussões práticas das teorias adotadas pelo Direito Civil que vinculam a imposição desse tributo. Ademais, deve-se dar a devida importância ao fator pessoal do IPTU, não o reduzindo à obrigação "carregada" por direito real (propter rem); entretanto respeitando, sob o olhar da segurança jurídica, o conceito que limita sua imposição no âmbito constitucional desse imposto.

\section{REFERÊNCIAS}

AMARO, Luciano. Direito tributário brasileiro. 16 ed. São Paulo: Saraiva, 2010.

ATALIBA, Geraldo. Hipótese de incidência tributária. 6 ed. São Paulo: Malheiros, 2010.

BALEEIRO, Aliomar. Direito Tributário Brasileiro. 11 ed. revista e atualizada por Misabel Abreu Machado Derzi. Rio de Janeiro: Forense, 2010.

Direito tributário brasileiro. 10 ed. revista e atualizada por Flávio Bauer Novelli. Rio de Janeiro: Forense, 1981.

BARRETO, Aires F. Curso de Direito Tributário municipal. São Paulo: Saraiva, 2009.

BARROSO, Luís Roberto. Interpretação e aplicação da Constituição: fundamentos de uma dogmática constitucional transformadora. 6 ed. rev. atual. e ampl. São Paulo: Saraiva, 2008.

BECKER, Alfredo Augusto. Teoria geral do Direito Tributário. 5 ed. São Paulo: Noeses, 2010.

BEVILÁQUA, Clóvis. Código Civil dos Estados Unidos do Brasil comentado. v. 3. 6 ed. Rio de Janeiro: Livraria Francisco Alves, 1942.

BOBBIO, Noberto. Teoria do ordenamento jurídico. 10 ed. Tradução Maria Celeste C. J. Santos. Brasília: Universidade de Brasília, 1999.

CÓdigo TRIBUTÁRIO NACIONAL E CONSTITUIÇÃO FEDERAL. 16 ed. São Paulo: Saraiva, 2010. 
COÊLHO, Sacha Calmon Navarro. Comentários à Constituição de 1988: sistema tributário. Rio de Janeiro: Forense, 1990.

GUIMARÃES, Deocleciano Torriere. Dicionário técnico jurídico. 11 ed. São Paulo: Rideel, 2008. MACHADO, Hugo de Brito. Curso de Direito Tributário. 32 ed. rev. atual. e ampl. São Paulo: Malheiros, 2011.

; MACHADO, Schubert de Farias. Dicionário de Direito Tributário. São Paulo: Atlas, 2011b. Lei complementar tributária. São Paulo: Malheiros, 2010.

. Comentários ao Código Tributário Nacional. v. 1. São Paulo: Atlas, 2003.

MACHADO, Hugo de Brito Segundo. Código Tributário Nacional: anotações à Constituição, ao Código Tributário Nacional e às leis complementares 87/1996 e 116/2003. 2 ed. São Paulo: Atlas, 2009.

MIRANDA, Francisco Cavalcanti Pontes. Tratado de Direito Privado. Direito das Coisas: Posse. Tomo X. Rio de Janeiro: Borsoi, 1971.

NADER, Paulo. Curso de Direito Civil. v. 4, Direito das Coisas. 2 ed. Rio de Janeiro: Forense, 2008.

NOVO CÓDIGO CIVIL: texto comparado. São Paulo: Harbra, 2003.

PACHECO, Angela Maria da Motta. "Sujeição passiva e responsáveis tributários.” IN: REVISTA DIALÉTICA DE DIREITO TRIBUTÁRIO. No 3. Dezembro de 1995.

RODRIGUES, Sílvio. Direito Civil: Direito das Coisas. v. 5. 11 ed. atual. São Paulo: Saraiva, 1994. SANTOS, Ernane Fidélis dos. "Comentários ao novo Código Civil, Vol. XV: da posse." IN: TEXEIRA, Sálvio de Figueiredo.(Org.) Comentários ao novo Código Civil. Rio de Janeiro: Forense, 2007.

SENADO FEDERAL. Constituição da República Federativa do Brasil. Brasília: Senado Federal, 2012.

SOUSA, Rubens Gomes. Compêndio de legislação tributária. 4 ed. São Paulo: Resenha Tributária, 1982.

\section{Notas}

1 Artigo orientado pelo professor Ms. Luis Dias Martins Filho. Procurador da Fazenda Nacional. Mestre em Direito pela Universidade de Cambridge - Reino Unido. Mestre em Direito Público pela Universidade Federal do Ceará. Professor da Faculdade Sete de Setembro.

2 Art. 34 - Contribuinte do imposto é o proprietário do imóvel, o titular do seu domínio útil, ou o seu possuidor a qualquer título. (Código Tributário Nacional)

3 Código Tributário Nacional e Constituição Federal. 16 ed. São Paulo: Saraiva, 2010. P. 8.

4 Ver seguinte ementa de decisão proferida pelo Tribunal de Justiça de Minas Gerais: AGRAVO DE INSTRUMENTO. DIREITO TRIBUTÁRIO. EXECUÇÃO FISCAL. IPTU. CONTRATO DE COMPRA E VENDA. POSSE COM ANIMUS DOMINI. O fato gerador do IPTU, prima facie, é a propriedade. [grifo próprio] Em casos excepcionais, quando efetivamente comprovada a posse de terceiro com animus domini, poderá este responder 
pelo imposto. A posse com animus domini, devidamente comprovada, contudo, não afasta a responsabilidade daquele que, no Registro de Imóveis, ainda figura como proprietário, podendo o legislador municipal eleger o sujeito passivo do tributo. Precedentes do Superior Tribunal de Justiça. Resp. 1111202/SP (Agravo de Instrumento 70048463988 RS , Relator: Carlos Roberto Lofego Canibal, Data de Julgamento: 19/04/2012, Primeira Câmara Cível, Data de Publicação: Diário da Justiça do dia 24/04/2012)

5 Novo Código Civil: texto comparado. São Paulo: Harbra, 2003. P. 220.

6 Veja as seguintes decisões do Superior Tribunal de Justiça: (721095 RJ 2005/0015069-5, Relator: Ministro MAURO CAMPBELL MARQUES, Data de Julgamento: 08/09/2009, T2 - SEGUNDA TURMA, Data de Publicação: DJe 24/09/2009); (744910 RJ 2005/0067735-9, Relator: Ministro HERMAN BENJAMIN, Data de Julgamento: 12/05/2009, T2 - SEGUNDA TURMA, Data de Publicação: DJe 21/08/2009); (811538 RS 2006/0011275-0, Relator: Ministro CASTRO MEIRA, Data de Julgamento: 06/03/2006, T2 - SEGUNDA TURMA, Data de Publicação: DJ 23.03.2006 p. 162); (944213 SP 2007/0089333-7, Relator: Ministro HERMAN BENJAMIN, Data de Julgamento: 05/02/2009, T2 - SEGUNDA TURMA, Data de Publicação: DJe 19/03/2009); . (865386 RJ 2006/0146024-8, Relator: Ministro CASTRO MEIRA, Data de Julgamento: 10/10/2006, T2 - SEGUNDA TURMA, Data de Publicação: DJ 19/10/2006 p. 286RSTJ vol. 205 p. 220); (1022580 RJ 2008/0009662-5, Relator: Ministra ELIANA CALMON, Data de Julgamento: 12/05/2009, T2 - SEGUNDA TURMA, Data de Publicação: DJe 29/05/2009).

7 Aires Fernandinho Barreto argumente o seguinte: "É dizer, não é toda e qualquer posse que pode ser submetida ao IPTU. Só se a de exigir o imposto do possuidor que detém a posse ad usucapionem, ou seja, a posse que pode condizir ao domínio.” (BARRETO, 2009, p. 216).

8 Observemos que o Supremo Tribunal Federal rejeitou entendimento na Súmula 74 (não mais vigora), dando origem a nova Súmula com entendimento oposto, a Súmula $\mathrm{n}^{\circ} 583$, a qual assim versa: Promitente-comprador de imóvel residencial transcrito em nome de autarquia é contribuinte do imposto predial territorial urbano.

9 Assim versando: Usufruto. Pagamento do IPTU.1. O usufrutuário, que colhe os proveitos do bem, é o responsável pelo pagamento do IPTU, nos termos do art. 733, II, do Código Civil, na proporção de seu usufruto.2. Recurso especial conhecido e provido. (203098 SP 1999/0009259-7, Relator: Ministro CARLOS ALBERTO MENEZES DIREITO, Data de Julgamento: 09/12/1999, T3 - TERCEIRA TURMA, Data de Publicação: DJ 08/03/2000 p. 106LEXSTJ vol. 130 p. 229RJADCOAS vol. 7 p. 85)

10 STJ - REsp 810800 MG 2006/0012684-9, Relator: Ministra ELIANA CALMON, Data de Julgamento: 16/08/2006, T2 - SEGUNDA TURMA, Data de Publicação: DJ 04.09.2006

11 STJ - AGRAVO REGIMENTAL NO RECURSO ESPECIAL 1069355 SP 2008/01339506, Relator: Ministro CASTRO MEIRA, Data de Julgamento: 11/11/2008, T2 - SEGUNDA TURMA, Data de Publicação: DJe 02/12/2008

12 STJ - REsp 618269 BA 2003/0223426-4, Relator: Ministro FRANCISCO FALCÃO, Data de Julgamento: 26/09/2005, T1 - PRIMEIRA TURMA, Data de Publicação: DJ 21.11.2005

13 AGRAVO REGIMENTAL NO RECURSO ESPECIAL 721095 RJ 2005/0015069-5, Relator: Ministro MAURO CAMPBELL MARQUES, Data de Julgamento: 08/09/2009, T2 - SEGUNDA TURMA, Data de Publicação: DJe 24/09/2009

14 STJ - REsp 811538 RS 2006/0011275-0, Relator: Ministro CASTRO MEIRA, Data de Julgamento: 06/03/2006, T2 - SEGUNDA TURMA, Data de Publicação: DJ 23.03.2006 
15 STJ - Resp 1115599 / SPMIN. ELIANA CALMOM.2.TURMA - Dje 13/05/2010 Ementa TRIBUTÁRIO - IPTU - SERVIDÃO DE PASSAGEM - OLEODUTOS - ART.34 DO CTN - POSSUIDOR - AUSÊNCIA DE TIPICIDADE - NÃO INCIDÊNCIA - SOLIDARIEDADE PASSIVA TRIBUTÁRIA - NECESSIDADE DE EXPRESSA PREVISÃO LEGAL INOCORRÊNCIA- RECURSO ESPECIAL NÃO PROVIDO. 1.O possuidor da servidão de passagem, embora detenha o direito de usar e gozar da propriedade, dela não pode dispor, razão pela qual não se insere no rol de contribuintes de IPTU previsto no art. 34 do CTN.[grifo próprio] 2.A solidariedade passiva tributária não se presume, devendo advir de previsão legal.

16 STJ - Resp 267099 BA 2000/0070300-1, Relator: Ministra ELIANA CALMON, Data de Julgamento: 16/04/2002, T2 - SEGUNDA TURMA, Data de Publicação: DJ 27/05/2002

17 TJMG -Agravo de Instrumento 70048463988 RS , Relator: Carlos Roberto Lofego Canibal, Data de Julgamento: 19/04/2012, Primeira Câmara Cível, Data de Publicação: Diário da Justiça do dia 24/04/2012

18 Artigo 34 do Código Tributário Nacional.

19 TRIBUTÁRIO. IPTU. RESPONSABILIDADE TRIBUTÁRIA. CONCESSIONÁRIA DE TERMINAL AEROPORTUÁRIO. POSSUIDOR POR RELAÇÃO DE DIREITO MATERIAL. ART. 34 DO CTN. INVIABILIDADE. PRECEDENTES. 34 CTN1. "A jurisprudência do STJ é pacífica no sentido de que o cessionário de serviço público aeroportuário, por ser possuidor do bem em virtude de relação de direito pessoal, não é contribuinte do IPTU, porquanto exerce a posse sem animus domini. 2. É inviável atribuir a responsabilidade tributária pelo recolhimento do IPTU à concessionária de terminal aeroportuário pertencente à União, tendo em vista que a concessão delegada pelo Ente Público não lhe transfere os poderes inerentes à propriedade. Precedentes do STJ. 3. Agravo Regimental não provido.” (744910 RJ 2005/0067735-9, Relator: Ministro HERMAN BENJAMIN, Data de Julgamento: 12/05/2009, T2 - SEGUNDA TURMA, Data de Publicação: DJe 21/08/2009)

20 A Tabela se embasa nos Municípios de maior arrecadação. Fortaleza foi inclusa devido à relevância pessoal atribuída pelos autores do presente artigo científico. Análise feita com base no exercício de 2009.

21 http://ww2.prefeitura.sp.gov.br/arquivos/secretarias/financas/legislacao/Decreto-52703-2011CLT.pdf Acesso em 27.abr.2012.

$22<$ http://smaonline.rio.rj.gov.br/legis_consulta/3916Dec\%2014327_1995.pdf> Acesso em 27.abr.2012.

$23<$ http://www.sf.saobernardo.sp.gov.br/web/guest/home> Acesso em 27.abr.2012.

$24<$ http://novo.guarulhos.sp.gov.br/files/LEI_6793.pdf> Acesso em 25.abr.2012.

$25<$ http://www.sefaz.salvador.ba.gov.br/generico/download/06\%2012\%2029\%20Lei\%20 7.186\%20-\%20CTRMS.pdf > Acesso em 28.abr.2012.

26 <http://www.sefin.fortaleza.ce.gov.br/legislacao/gerados/leis/Lei $\% 20$ n $\%$ C2\%BA $\% 204.144$ Atualizada\%20at\%C3\%A9\%20LC\%20n\%C2\%BA\%2059.pdf > Acesso em 25.abr.2012.

$27<$ http://www.oabpe.org.br/comunicacao/artigos/7115-a-verdade-e-a-ocupacao-dos-terrenosde-marinha-danilo-oliveira-r-de-lima-.html> Acesso em: 2.mai.2012.

28 STJ - Resp 1115599 / SPMIN. ELIANA CALMOM. 2.TURMA - Dje 13/05/2010 
TAX ON REAL ESTATE PROPERTY: AN ANALYSIS UNDER THE BRAZILIAN CONSTITUTION

Abstract: The central theme is about the passive subjection arising from the obligation that requires the payment of tax on real estate property (IPTU), facing issues that involve as much the taxpayer as the tax collection system itself.

Keywords: Responsibility. Taxpayer. Brazilian Constitution. IPTU 